\title{
Villin: A Marker for Development of the Epithelial Pyloric Border
}

\author{
EVAN M. BRAUNSTEIN, XIAOTAN T. QIAO, BLAIR MADISON, KATHLEEN PINSON, LAURA DUNBAR, \\ AND DEBORAH L. GUMUCIO* \\ Department of Cell and Developmental Biology, University of Michigan, Ann Arbor, Michigan
}

\begin{abstract}
In the adult gastrointestinal tract, the morphologic borders between esophagus and stomach and between stomach and small intestine are literally one cell thick. The patterning mechanisms that underlie the development of these sharp regional divisions from a once continuous endodermal tube are still obscure. In the embryonic endoderm of the developing gut, region-specific expression of certain genes (e.g., intestine-specific expression of the actin bundling protein villin) can be detected as early as 9.0 days post coitum, although the morphologic differentiation of the gut epithelium proper does not begin until 4 to 5 days later. By using a mouse model in which a $\beta$-galactosidase marker has been inserted into the endogenous villin locus, we examined the development of the stomach/ intestinal (pyloric) border during gut organogenesis. The data indicate that the border is not sharp from the outset. Rather, the initial border region is characterized by a decreasing gradient of villin/ $\beta$-galactosidase expression that extends into the distal stomach. A sharp epithelial border of villin/ $\beta$-galactosidase expression appears abruptly at day 16 and is further refined over the next 3 weeks to form the distinct onecell-thick border characteristic of the adult. These results indicate that an important previously unrecognized patterning event occurs in the gut epithelium at 16 days; this event may define an epithelial compartment boundary between the stomach and the intestine. The villin/ $\beta$-galactosidase mouse model characterized here provides an excellent substrate with which to further dissect the mechanisms involved in this patterning process. ๑ 2002 Wiley-Liss, Inc.
\end{abstract}

Key words: intestine; endoderm; compartment boundary

\section{INTRODUCTION}

The formation of the embryonic gut occurs similarly in all vertebrates (Rosenquist 1971; Lawson and Pederson 1987; Keller 1976; Smith et al., 2000). After gastrulation, definitive endoderm cells that will form the primitive gut migrate from the anterior end of the primitive streak (Rosenquist, 1971; Lawson, 1987). The foregut and hindgut primordia are formed by an infold- ing of endodermal cells at the anterior and posterior regions of the embryo. The two open-ended portals formed from this process, the anterior and posterior intestinal portals (AIP and CIP, respectively) extend toward one another, eventually fusing to form a closed tube, which is regionalized into foregut, midgut, and hindgut. As the embryo develops, the foregut will give rise to the esophagus, stomach, and several peripheral organs, including the lungs, pancreas, and liver; the midgut will give rise to the small intestine, and the hindgut will form the large intestine (reviewed in Wells and Melton, 1999).

Regional patterning along the anterior-posterior axis of the gut is known to involve crosstalk between the endodermal and mesodermal cells that comprise the gut tube (reviewed in Kedinger et al., 1998). Thus in grafts composed of dissociated and recombined tissues, small intestinal mesoderm is able to program presumptive stomach or colonic endoderm to adopt the morphology of small intestine, although this reprogramming has a limited temporal window. Likewise, small intestinal endoderm can instruct stomach mesenchyme to participate in the generation of the musculature and villus structure that characterize the small intestine. The region-restricted morphologic effects of this crosstalk are first observed in the mesoderm; by 10 days post coitum (dpc) in the mouse, a thickening of the stomach mesoderm, relative to the nearby esophageal or intestinal mesoderm, is visible. Only later $(\sim 14 \mathrm{dpc})$ does the endoderm begin to take on its future regionally distinct morphology (e.g., in the small intestine, development of villi and remodeling of the epithelium from a multilayered squamous character to a single layer of columnar cells). Further maturation of the intestinal epithelium continues with crypt development and is not complete until after birth.

Grant sponsor: NIH; Grant number: T32-HL07505; Grant sponsor: Roger DeMeritt Research Fund, University of Michigan Comprehensive Cancer Center; Grant sponsor: Dean's Fellowship from the University of Michigan Center for Organogenesis; Grant sponsor: NIH Training Program in Organogenesis.

* Correspondence to: Deborah L. Gumucio, University of Michigan Medical School, Department of Cell and Developmental Biology, 5704 Medical Science II, Ann Arbor, MI 48019-0616.

E-mail: dgumucio@umich.edu

Received 31 July 2001; Accepted 22 February 2002

DOI 10.1002/dvdy.10091 
One of the most remarkable features of the regional differentiation process in the gut is its dramatic outcome: extremely sharp epithelial boundaries develop at several discrete points. These boundaries arise in what was once a morphologically continuous endodermal tube, and in the adult, they are literally one cell thick. At the pylorus for example, a cell with all of the characteristics of stomach epithelium lies immediately next to a cell with a distinct duodenal phenotype. The molecular aspects underlying this regionalization process are largely unknown, but insight into the underlying mechanisms could also be relevant to situations in which the patterning is disrupted. For example, lesions known as intestinal metaplasias develop in stomach and esophagus; these lesions represent a conversion of those epithelia to resemble intestine.

Here, we examine the formation of the pyloric epithelial boundary during mouse fetal development, by using the villin gene as a marker of small intestinespecific gene expression. Villin is an actin bundling protein that is found in many absorptive epithelia. Importantly for these studies, villin is expressed in the presumptive small intestinal epithelium several days before intestinal villi appear (Maunoury et al., 1988, 1992; Ezzell et al., 1989). During further tissue patterning and villus formation, villin is up-regulated. In the adult, all cells of the intestinal epithelium express villin and the concentration of villin increases as cells move from the crypt to the tip of the villus (Maunoury et al., 1992). Thus the villin gene appears to respond to many of the morphogenic cues that accompany intestinal organogenesis: tube formation and regionalization, remodeling of the epithelium, as well as the constant program of cell proliferation and differentiation that characterizes the adult intestine. Therefore, it is likely that the molecular factors that control villin gene expression during these processes are the patterning factors themselves and that the study of villin gene regulation could shed light on these processes.

We previously described a mouse model in which the endogenous villin gene is disrupted by insertion of a cDNA for $\beta$-galactosidase (Pinson et al., 1998). Except for subtle ultrastructural alterations in the microvillar actin core of the intestine, no major phenotype accompanies the loss of villin protein and insertion of $\beta$-galactosidase in the mouse. The mice breed and thrive, and development is normal. Moreover, villin/ $\beta$-galactosidase expressing cells are easily detectable by staining with X-gal, both in whole embryos and in sections. Thus the documentation of the expression patterns of villin/ $\beta$-galactosidase in this mouse model, as reported here, provides an important tool for investigation of the downstream effects of genetic alterations that affect the development of any of the tissues in which villin/ $\beta$-galactosidase is expressed.

Here, we focus mainly on the developing pyloric region. The objective of these studies was to learn whether a sharp border of villin expression is formed at the pyloric region from the outset of villin expression or whether the boundary is initially diffuse and is later refined to a sharp border. The answer to this question can have important implications with regard to the possible molecular mechanisms that act to set this distinct epithelial boundary. Our results extend earlier in situ and immunocytochemical studies that documented villin expression in the early gut tube and in kidney and gonad primordia (Maunoury et al., 1988, 1992; Ezzell et al., 1989). In addition, we observed $\beta$-galactosidase activity as well as endogenous villin protein expression in the developing auditory system, where it had not been previously documented. $\beta$-Galactosidase expression was also seen in the choroid plexus of the brain and in the tail gut, but endogenous villin protein could not be detected by immunostaining at these sites. In the tail gut, $\beta$-galactosidase-positive cells were seen in the mesenchyme before its condensation to form the tail gut structure; thus this villin/ $\beta$ galactosidase mouse model provides an important tool for the further molecular investigation of the mesenchymal to endothelial transition characteristic of the tail gut.

\section{RESULTS \\ $\beta$-Galactosidase Expression in Early (6.5-8.5 dpc) Mouse Embryos}

Whole-mount embryos at $6.5 \mathrm{dpc}$ show intense $\beta$-galactosidase staining in the extraembryonic visceral endoderm, and discontinuous staining of individual cells in the embryonic visceral endoderm (Fig. 1A,B). At the onset of gastrulation, approximately $7.5 \mathrm{dpc}$, definitive embryonic endodermal cells ingress from the primitive streak. These cells displace cells of the primitive visceral endoderm and line the entire ventral surface of the embryo with definitive endoderm that will form the gut (Lawson and Pedersen, 1987). $\beta$-Galactosidase-positive cells were only detected within extraembryonic tissues of early and late gastrulating 7.5-8.0 dpc embryos.

At $8.5 \mathrm{dpc}$, scattered cells positive for $\beta$-galactosidase staining are visible in the forming AIP (Fig. 1C-F). These stained cells likely represent embryonic visceral endoderm cells that are slowly being displaced by ingressing definitive endoderm cells. In sectioned embryos, these cells are seen in the AIP and CIP in open (Fig. 1E) as well as closed (Fig. 1F) regions of the foregut and hindgut.

\section{$\beta$-Galactosidase Expression in the Developing Intestine}

The first clearly embryonic staining that we observed was in $9.0 \mathrm{dpc}$ embryos, in the ventral portions of the closed hindgut, where this structure contacts the vitelline artery (Fig. 2A). This ventral staining was confirmed by immunohistochemical staining of villin protein (Fig. 2B). By $9.5 \mathrm{dpc}$, staining was seen in all cells of the hindgut, and in whole-mount embryos of 9.5 dpc, staining is prominent in the hindgut (Fig. 2C). By $10.5 \mathrm{dpc}$, the entire midgut and hindgut area is visibly 

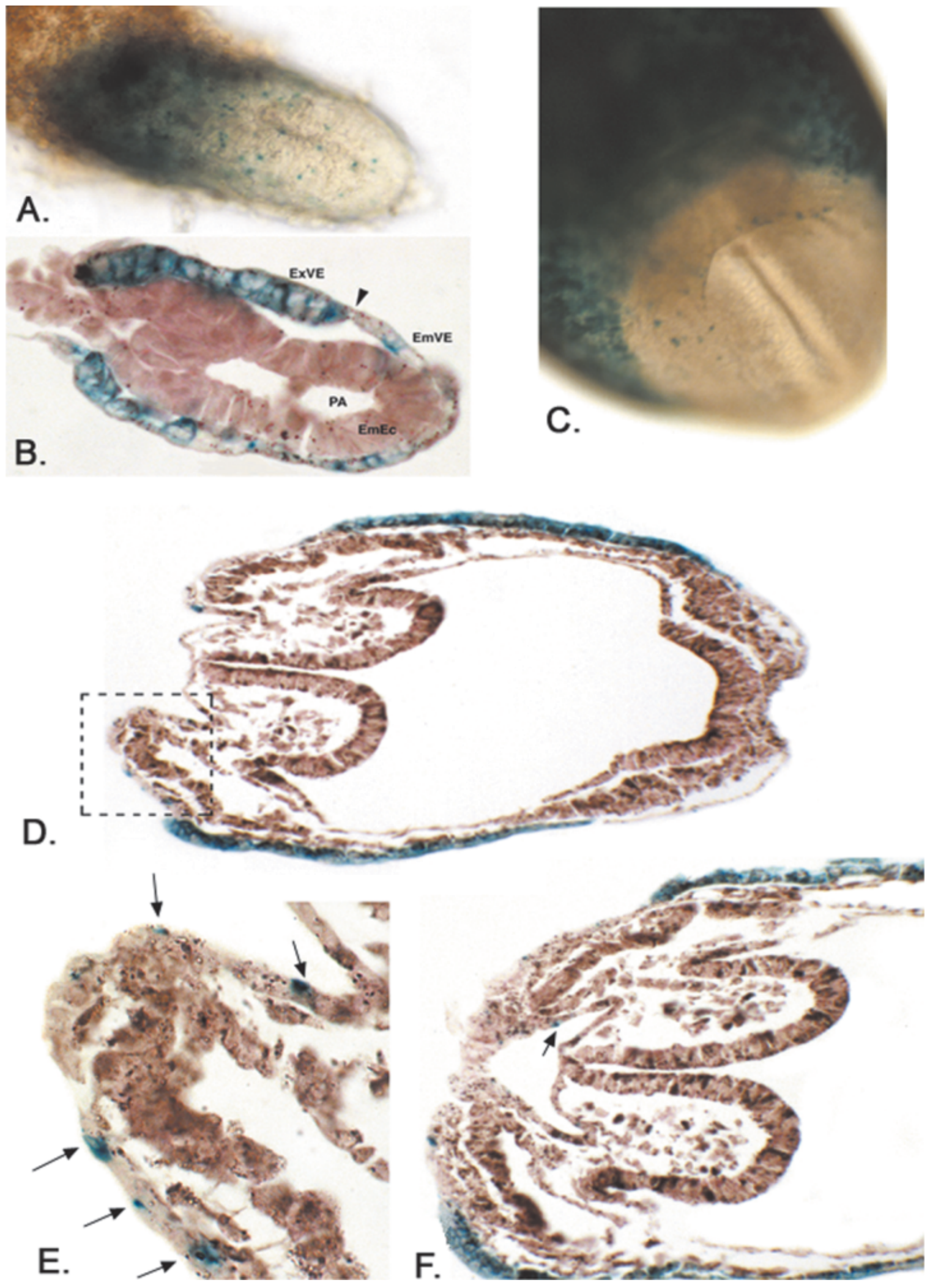

Fig. 1. Expression of $\beta$-galactosidase in early mouse embryos. A: Wholemount egg cylinder at 6.5 days post coitum (dpc). B: Sagittal section of a 6.5 dpc egg cylinder. The extraembryonic visceral endoderm (ExVE) stains strongly for $\beta$-galactosidase; scattered positive cells are also seen in the embryonic visceral endoderm (EmVE). The arrowhead indicates the transition from extraembryonic to embryonic visceral endoderm. In addition to a border of $\beta$-galactosidase expression, this transition is also characterized by a change in cell morphology (columnar in extraembryonic visceral endoderm and squamous in embryonic visceral endoderm). PA, preamniotic cavity; EmEc, embryonic ectoderm. C: Whole-mount 8.5 dpc embryo, late head fold stage. The opening of the anterior intestinal portal is shown. Scattered $\beta$-galactosidase positive cells can be seen in and around the portal. D-F: Transverse sections through an $8.5 \mathrm{dpc}$ embryo. The embryo shown has not yet undergone turning. Scattered $\beta$-galactosidase-positive cells are located in the open presumptive foregut pocket ( $D$ and enlarged in $E$ ) and can also be seen in a more caudal section of the foregut diverticulum (arrow in F). 

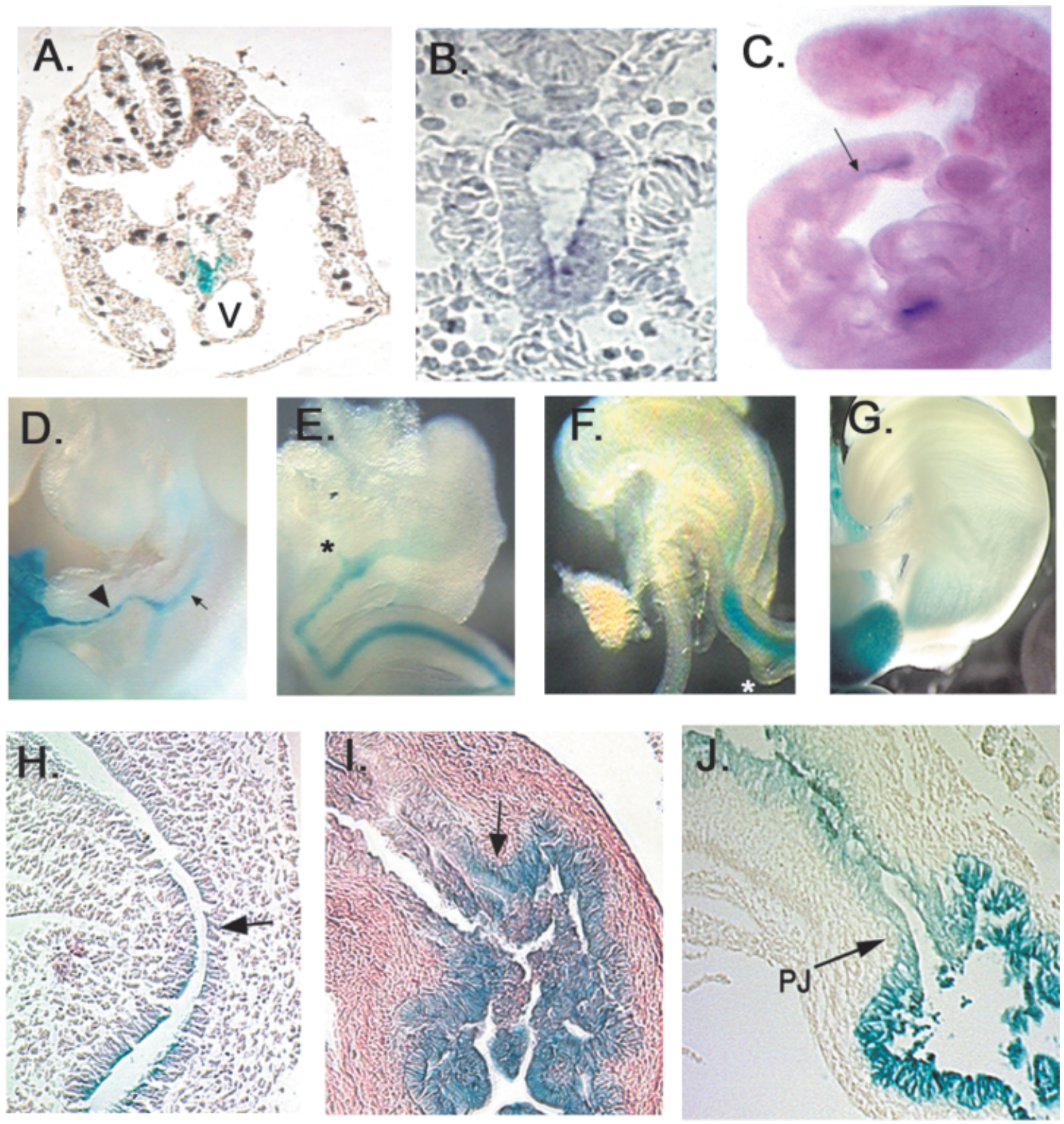

Fig. 2. A: Hindgut region of a 9.0 days post coitum (dpc) embryo. $\beta$-Galactosidase-positive cells are observed mainly on the ventral side of the hindgut, in the area where it contacts the vitelline artery (V). B: Hindgut region of a $9.0 \mathrm{dpc}$ embryo immunostained for villin protein expression. The section is from a level slightly rostral to the region of fusion of the two distal trunks of the dorsal aortae to form the vitelline artery (V). Ventral staining is again apparent. C: Whole-mount embryo of $9.5 \mathrm{dpc}$. Note staining in the hindgut (arrow). The stained region in the midgut represents the region of the vitelline duct, which has been broken off. D: Whole-mount embryo of $10.5 \mathrm{dpc}$. The vitelline duct is strongly positive (arrowhead) and connects to the equally positive yolk sac (at far left). The midgut is also positive (arrow) throughout its length. E: Viscera of embryo at $11.5 \mathrm{dpc}$. The asterisk marks the pancreatic duct. Staining extends beyond this point and into the presumptive stomach. The forestomach and esophagus are negative for $\beta$-galactosidase. F: Viscera of embryo at $13.5 \mathrm{dpc}$, showing intense staining in the intestine and weaker staining in the distal stomach. The asterisk marks the pancreatic duct. G: Viscera of embryo at $15.5 \mathrm{dpc}$. Staining in the intestine has intensified, sharpening the apparent border between stomach and intestine. H: Section of the presumptive pyloric region in a $10.5 \mathrm{dpc}$ embryo. Apical staining can be detected in the intestinal region (bottom half of the picture); staining gradually fades into the stomach (top half). The approximate pyloric border (as determined by the thickening of the mesoderm in the stomach region) is marked by the arrow. I: Cryostat section of the pyloric region in a $15.5 \mathrm{dpc}$ embryo. Note that there is still not a distinct border between the intensely stained intestine and the lesser stained regions of stomach. J: Paraffin embedded section of a $15.5 \mathrm{dpc}$ embryo at the pyloric region. No distinct border of staining is visible. PJ, pyloric junction. 
stained (Fig. 2D). In addition, continuous staining is observed in the yolk sac and along the vitelline duct as it enters the midgut region (Fig. 2D). From 11.5 to 14 dpc, the epithelial lining of the intestine and stomach are not morphologically distinct from one another, although the stomach mesenchyme has thickened to create the form of the stomach. Whole-mount embryos reveal increases in the intensity of $\beta$-galactosidase expression in the intestine that seem to sharpen the apparent anterior border significantly in whole-mounts (Fig. $2 \mathrm{E}-\mathrm{G})$. However, $\beta$-galactosidase staining in the distal stomach is still visible in these whole-mount tissues.

Sections of $10.5 \mathrm{dpc}$ viscera confirm that staining is present in the presumptive small intestinal epithelium and that the staining pattern does not show a sharp anterior border of expression at the pyloric border. Rather, staining gradually decreases from intestine to distal stomach across the presumptive pyloric border (Fig. 2H). Regions of the anterior stomach and esophagus are unstained (not shown). By 14.5-15.5 dpc, the intestinal epithelium begins to develop villi and can now be morphologically distinguished from stomach epithelium. However, both cryostat and paraffin-embedded sections reveal that, even at $15.5 \mathrm{dpc}$, the epithelium has not yet developed the sharp (one-cellthick) border of villin expression characteristic of the adult (Fig. 2I,J). Intense staining in the intestinal region fades gradually into the distal stomach.

Interestingly, Figure 2B,H shows that $\beta$-galactosidase staining is localized to the apical portion of intestinal epithelial cells. Apical localization of both villin mRNA (Landry et al., 1994) and protein (Maunoury et al., 1992) has been previously demonstrated. Because the expressed villin/ $\beta$-galactosidase fusion transcript created by the genomic $\beta$-galactosidase cDNA insertion includes intact untranslated $5^{\prime}$ sequences and because the fusion protein itself contains 18 amino acids from villin's exon 1 , these nucleotides and/or amino acids may be responsible for apical targeting.

\section{Abrupt Appearance of a Distinct Epithelial Pyloric Border}

At $16.5 \mathrm{dpc}$, a sharpening of the epithelial pyloric border is abruptly observed. The border appears at first to be imperfect; scattered cells anterior to the presumptive border also appear to stain for $\beta$-galactosidase (Fig. 3A). Over the next several days, the border becomes more distinct (Fig. 3B-D). Staining of 3-weekold mouse tissue reveals the characteristic one-cellthick distinct border of $\beta$-galactosidase activity at the pyloric junction (Fig. 3E). Crypt development in the mouse is known to be complete at this time.

In both heterozygotes and homozygotes, the stained epithelial border forms a straight line (Fig. 3F). This straight line is not as obvious in sections due to the convolutions of the epithelium (but see Fig. 3C). It has been noted previously that boundaries between compartments are often straight (reviewed in Dahmann and Basler, 1999). Taken together with recently published data that indicate the presence of a compartment boundary in the mesoderm of the pyloric region (Smith and Tabin, 2000), our data suggest that the pyloric epithelial border may also represent a compartment boundary.

Cryostat sections confirm $\beta$-galactosidase expression in crypts as well as on villi (Fig. 3G). Cells of all four lineages are stained, and staining is more intense on villus tips than in crypts. This crypt to tip gradient corroborates earlier studies of villin mRNA and protein expression in the intestine (Boller et al., 1988; Landry et al., 1994).

\section{Expression in Urogenital Tissue}

An elegant earlier study documented the timing and location of villin expression in the developing urogenital tissues (Maunoury et al., 1992). Here, we highlight only a few aspects of this expression, which corroborate earlier findings, to validate this villin/ $\beta$-galactosidase model as a tool for the further exploration of the development of these systems. Mesonephros first appear in the mouse embryo around $9.5 \mathrm{dpc}$. However $\beta$-galactosidase staining was not seen in these structures until $11.5 \mathrm{dpc}$. Whole-mount tissues and sections at 12.5 and $13.5 \mathrm{dpc}$ show strong staining that is confined to the epithelium in mesonephric tubules (Fig. 4A,B), whereas no staining is detected in mesonephric ducts (not shown). Staining in the metanephric region of the developing kidney is first seen at day 14.5. By $15.5 \mathrm{dpc}$, numerous tubules and ducts are present. Sections of convoluted, but not straight tubules are distinctly positive for $\beta$-galactosidase (Fig. 4C). Whole-mount 15.5 dpc kidneys reveal specific $\beta$-galactosidase staining in tubules of the cortex (Fig. 4D). Sections of adult kidney exhibit $\beta$-galactosidase staining that is restricted to proximal convoluted tubules (Fig. 4E). We also detected $\beta$-galactosidase staining in other portions of the developing urogenital system, including the genital protuberance, the forming urogenital sinus, and the developing urethra (data not shown).

\section{$\beta$-Galactosidase Expression in Other Tissues}

$\beta$-Galactosidase staining was detected in the developing auditory system. Particularly intense staining was observed in the endolymphatic duct (Fig. 4G), and moderate staining was visible in the differentiating neuroepithelium of the basal region of the cochlear canal (Fig. 4H). Because expression of villin in these regions had not been previously documented, these tissues were re-examined by immunohistochemical staining for villin protein. Although protein expression was clearly visible in the developing basal cochlear epithelium (Fig. 4I), endolymphatic ducts were not stained (data not shown). Similarly, expression of $\beta$-galactosidase was clearly visible in the ventricles of the developing brain, in the choroid plexus (Fig. 4F, G), but this structure was negative for villin protein expression as detected by immunohistochemistry. 

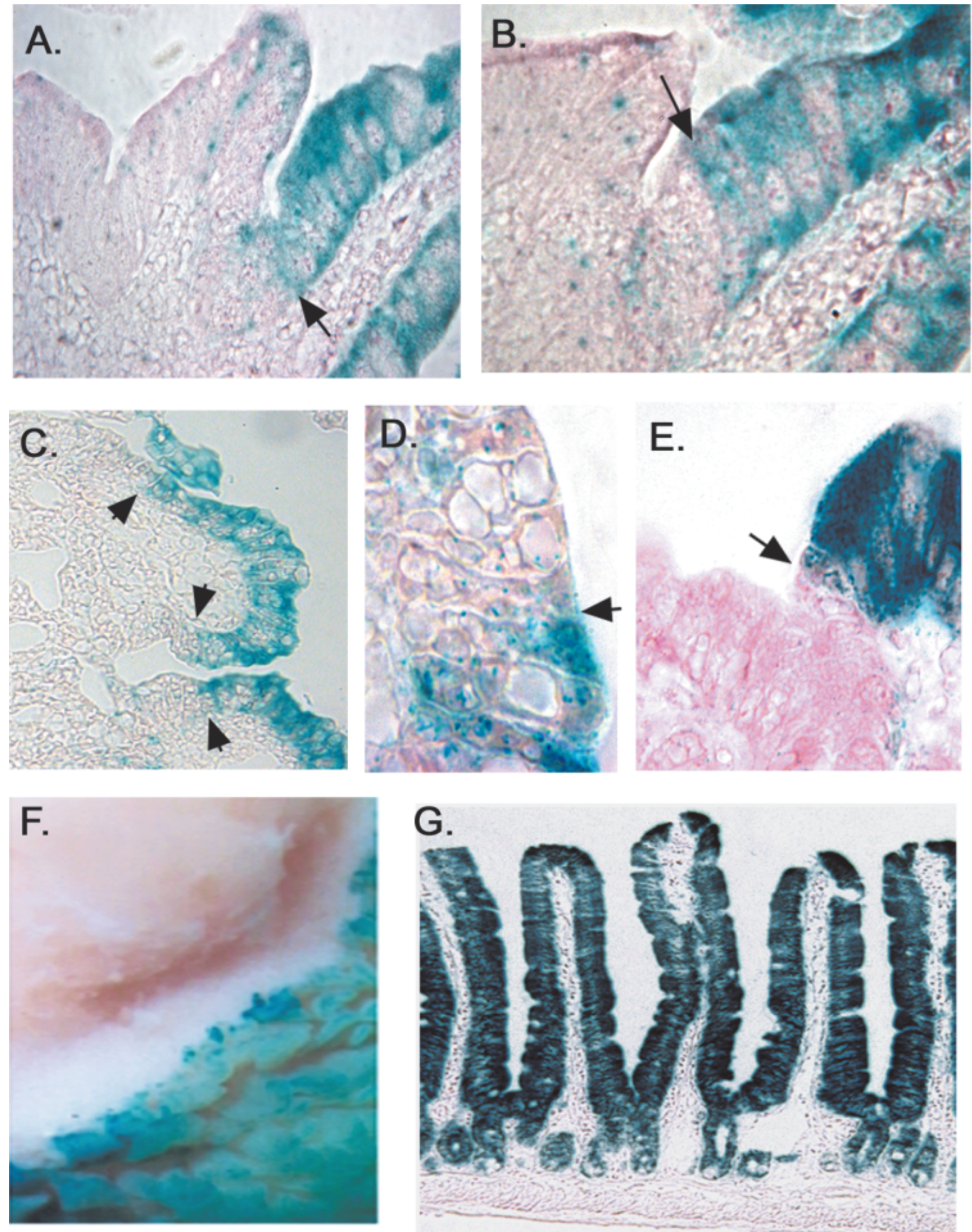

Fig. 3. Attainment of a one-cell-thick epithelial pyloric border. A: Cryostat section of the pyloric region of a 16.5 days post coitum (dpc) embryo. The arrow indicates a position where a continuous row of stained cells is suddenly interrupted by unstained cells. Further to the left of the arrow, some stained cells can still be discerned, as if the border is not yet completely set. B: Cryostat section of the pyloric region of a $17.5 \mathrm{dpc}$ embryo. The distinct border is again apparent. Less staining is visible in presumptive stomach cells. C: Cryostat section of the pyloric region of a
18.5 dpc embryo. The sharp border is observed at several points along the epithelium (arrows). D: Higher magnification of a border region from a 18.5 day embryo. E: The epithelial pyloric border of a 3-week pup is clearly established (arrow). F: Whole-mount stained tissue from the pyloric region of a 3-week old pop. Note the straight border of staining. G: The intestinal epithelium of a 3-week pup reveals staining in all cells of the epithelium, in crypt and tips. Staining is more intense on villi than in crypts. 

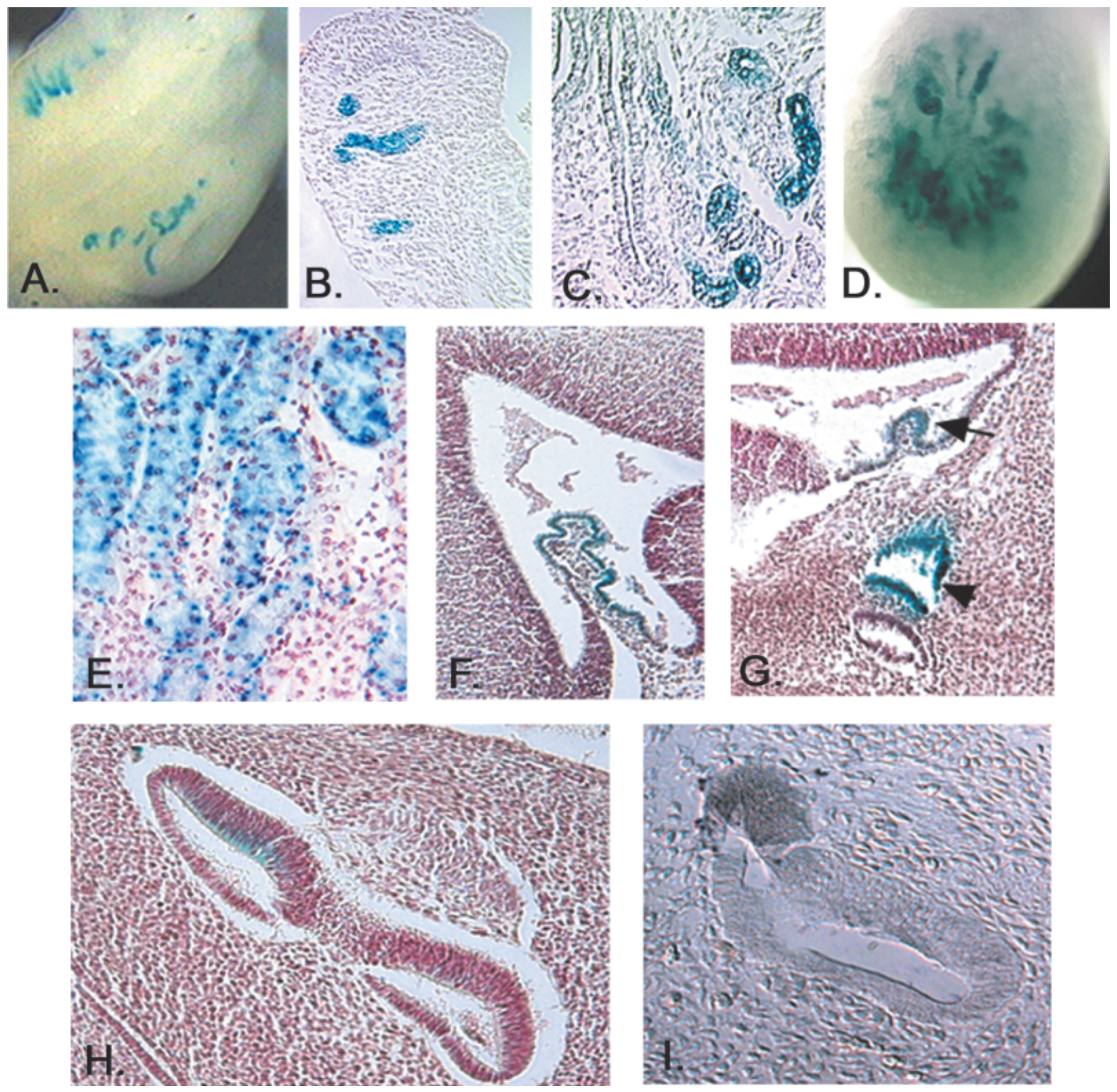

Fig. 4. $\quad \beta$-Galactosidase expression in developing genitourinary, brain, and auditory tissues. A: Whole-mount staining of viscera dissected from a 12.5 days post coitum $(\mathrm{dpc})$ embryo reveals tubular staining in the mesonephric areas. B: Sectioned $13.5 \mathrm{dpc}$ mesonephros exhibits staining in mesonephric tubules. C: Section of metanephric kidney at $15.5 \mathrm{dpc}$ shows staining in convoluted tubules but not straight collecting ducts. D: Kidney of a 15.5 day embryo. The kidney has been cut in half, then stained to reveal developing convoluted tubules in the cortex. E: Paraffin section of adult kidney. Staining is confined to convoluted tubules. F: The choroid plexus of the fourth ventricle of the brain of a $13.5 \mathrm{dpc}$ embryo stains positively for $\beta$-galactosi- dase. G: Oblique section of the head of a $13.5 \mathrm{dpc}$ embryo showing staining in choroid plexus (arrow) and endolymphatic duct (arrowhead). The unstained structure below the endolymphatic duct is a portion of a semicircular canal. H: Developing cochlea of a $13.5 \mathrm{dpc}$ embryo. This neuroepithelium will eventually develop into hair cells and supporting cells. Staining is present in the basal regions only as the cochlea undergoes its first turn. This staining may follow a maturation sequence, as the cochlea is known to mature from the basal region to the apex (Lim and Anniko, 1985). I: Immunostaining for endogenous villin protein in a wild-type $\mathrm{C} 57 \mathrm{BI} / 6 \mathrm{~J}$ mouse confirms staining in the basal neuroepithelium of the developing cochlea.
Finally, $\beta$-galactosidase expression was detected in the tail bud. In vertebrate embryos, the tail bud is an aggregate of mesenchymal cells located at the very caudal end of the embryo. It forms from an undifferen- tiated mass of mesenchymal cells derived from remnants of the primitive streak and Henson's node (see Griffith et al., 1992, and Gajovic et al., 1993, for review). Within tail bud tissue, three condensations form 
and develop into the tail notochord, the tail gut, and the secondary neural tube. In the latter two structures, the cells condense into rosette patterns that eventually cavitate to produce a lumen. On serial sections of 10.5 dpc embryos stained for $\beta$-galactosidase, we observed distinct staining in a cluster of undifferentiated mesenchymal cells in the distal tail bud. Serial sections (moving in a rostral direction) revealed that these mesodermal cells are condensing to form the tail gut structure, which is also positive for $\beta$-galactosidase (Fig. 5A-E). No $\beta$-galactosidase staining was seen in mesenchymal cells around or within the caudal neural tube or notochord (Fig. 5E). Thus as suggested by earlier fate mapping studies in chick and mouse (Catala et al., 1995; Wilson and Beddington, 1996), a distinct set of mesenchymal cells seems to be destined to form the tail gut structure, and expression of the villin/ $\beta$-galactosidase allele marks these cells specifically. This finding represents the only region of the embryo in which $\beta$-galactosidase staining is seen in mesenchymal cells. Although villin/ $\beta$-galactosidase staining is also seen in cells of the developing kidney that undergo a mesodermal to epithelial transition, $\beta$-galactosidase is not expressed in kidney cells until after epithelialization is complete. In contrast, in the case of the tail gut, $\beta$-galactosidase expression precedes epithelial transformation. Although the apical ends of tail gut cells possess microvilli and might be expected to express villin (Gajovic et al., 1993), re-examination of the tail bud region after immunohistochemical staining with an anti-villin antibody did not reveal endogenous villin protein in these structures.

The clear expression of $\beta$-galactosidase protein in the face of the apparent absence of endogenous villin protein in the choroid plexus and tail gut could be due to differences in the sensitivity of these two assays (the $\beta$-galactosidase staining procedure is far more sensitive). However, this is unlikely to be the case for the endolymphatic duct, where $\beta$-galactosidase staining was particularly intense. Alternatively, insertion of the $\beta$-galactosidase cDNA (or adjacent neomycin resistance gene) into the villin locus and/or the accompanying loss of an endogenous 4-kb region of the endogenous villin gene may have disturbed the normal regulatory pattern of this locus so as to cause ectopic $\beta$-galactosidase expression specifically in these tissues. Nevertheless, that $\beta$-galactosidase is reproducibly expressed in these structures (and not in control mice) indicates that this villin/ $\beta$-galactosidase mouse model can provide a valuable tool for the further investigation of the development of these tissues. This is particularly interesting in the case of the tail gut, where the villin/ $\beta$-galactosidase allele provides a potential lineage marker for mesenchymal cells destined to form the tail gut structure.

\section{DISCUSSION}

One way to gain insight into the process of organogenesis is to study the patterns of expression and reg- ulation of tissue-specific genes during organ development. Particularly useful are genes that initiate expression upon organ anlage formation and exhibit additional regulatory changes in accord with developmental events associated with tissue patterning. For example, the study of albumin expression provided important insights into liver development (reviewed in Zaret, 2000), whereas the study of insulin expression led to an improved understanding of the factors that regulate development of the pancreas (reviewed in Huang and Tsai, 2000). We propose that villin is an excellent model gene for the study of intestinal epithelial organogenesis and that the mouse model characterized here provides a valuable tool for the molecular dissection of that complex process.

Villin/ $\beta$-galactosidase expression (as well as endogenous villin protein expression) was first detected in the ventral portion of the developing hindgut, where this structure contacts the vitelline artery. Evidence that the dorsal and ventral regions of the hindgut are patterned differently have also been presented by Maatman et al. (1997) in an analysis of Danforth's short tail mutation $(S d)$, a semidominant mutation that results in alterations of the axial skeleton and urogenital system. In chimeric mice produced by using $S d+/$ - and -/ES cells, the mutant cells were specifically excluded from the ventral portion of the hindgut in $9.5 \mathrm{dpc}$ embryos, whereas dorsal regions of the hindgut were well populated with mutant cells. These data clearly indicate different requirements for the $S d$ gene product in dorsal and ventral cells. That cells on the ventral aspect of the hindgut lie next to endothelial cells of the vitelline artery is also of interest since recent work indicates that endothelial cells are required for organogenesis of the liver (Matsumoto et al., 2001) and pancreas (Lammert et al., 2001). The question of whether the ventral expression of villin, or more generally, the dorsal/ventral patterning of the hindgut is secondary to an inductive signal from this specific population of endothelial cells could be further studied by using the villin/ $\beta$-galactosidase mouse model described here.

The molecular factors that control villin expression during the further development of the small intestine are not known, but potential regulatory candidates are $\mathrm{Cdx} 1, \mathrm{Cdx} 2$, and $\mathrm{Pdx} 1 . \mathrm{Cdx} 1$ and $\mathrm{Cdx} 2$ are members of the caudal family of transcription factors. Like villin, $\mathrm{Cdx} 2$ is expressed initially in the hindgut, and its expression domain expands rapidly to include the entire midgut and hindgut by $9.5 \mathrm{dpc}$ (Beck et al., 1995). Later expression of $\mathrm{Cdx} 2$ is also similar to villin expression in that both molecules are expressed at higher levels in proximal than distal intestine (James et al., 1994; Silberg et al., 2000). The related gene, $\mathrm{Cdx} 1$, is activated later in intestinal development $(14.5 \mathrm{dpc})$ and is predominant in distal intestine. $\mathrm{Cdx} 1$ expression is largely confined to crypts (Silberg et al., 1997), whereas Cdx2 expression is predominant on villus tips. Villin is expressed in all cells of the crypts and tips, although a 

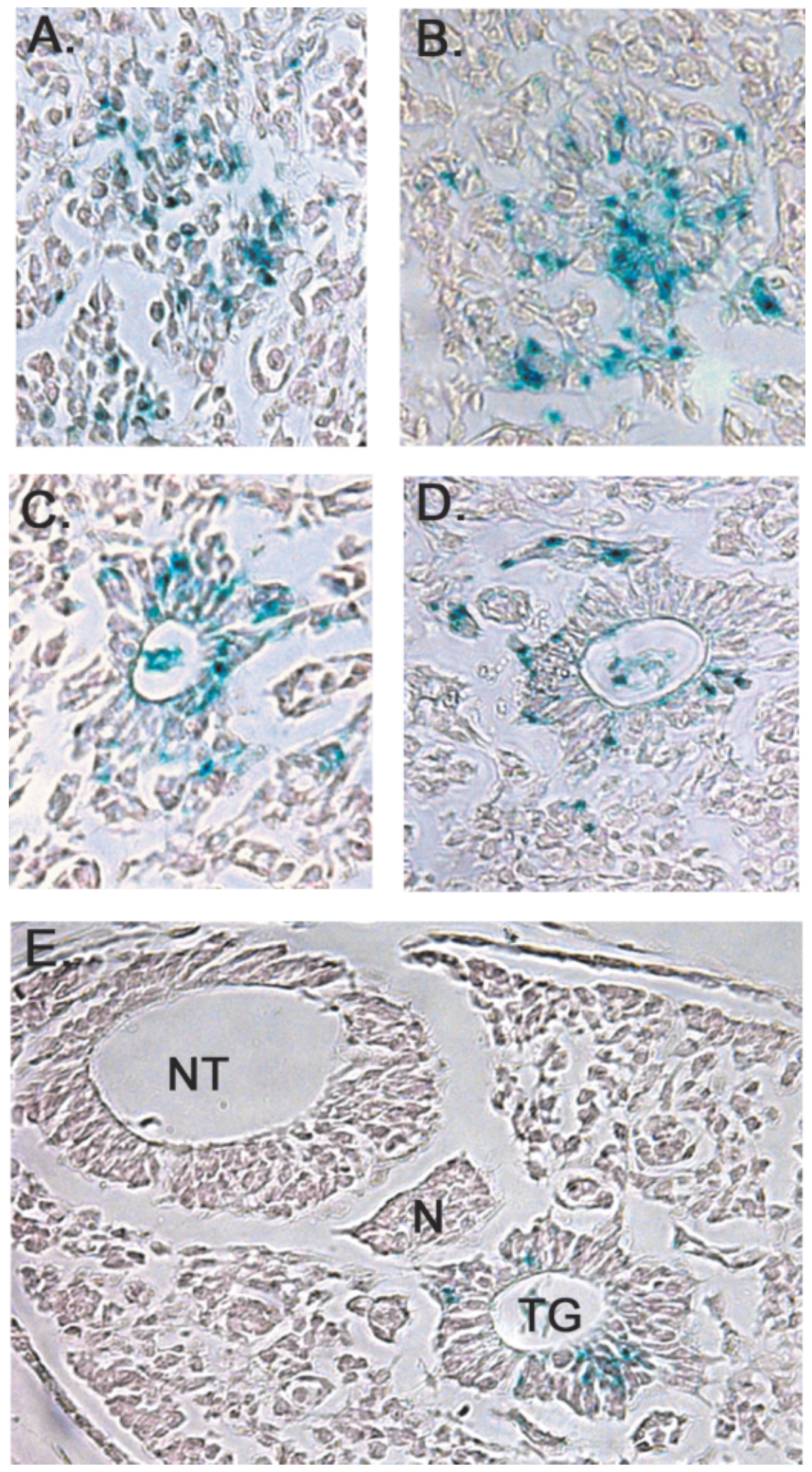

Fig. 5. The developing tail gut in a 10.5 days post coitum (dpc) embryo. A-E represent sections moving from caudal to rostral. Scattered mesenchymal cells $(A, B)$ can be seen to coalesce into a vesicle (first visible in $B$ ). The vesicle epithelium is one layer thick, and cells have the appearance of epithelial cells at their apex (next to the lumen) and of mesodermal cells at their base (C-E). In the most rostral section $(E)$, the secondary neural tube (NT) and notochord (N) are visible. Only the tail gut (TG) is stained.

clear increase in expression is noted as cells differentiate in the vertical axis. Interestingly, all three genes-villin, as well as $\mathrm{Cdx} 1$ and $\mathrm{Cdx} 2$-are coordinately expressed in metastatic tumors derived from the colon (Giordano et al., 2001). Thus, villin may be a target of $\mathrm{Cdx} 1 / \mathrm{Cdx} 2$ regulation; indeed, the villin promoter and first intron contain numerous potential $\mathrm{Cdx}$ binding sites (data not shown). 
Although the expression patterns of $\mathrm{Cdx} 1$ and $\mathrm{Cdx} 2$ in the developing intestine do not seem to account for the abrupt development of a sharp epithelial border of villin/ $\beta$-galactosidase expression at 16 days, it is interesting to note that $\mathrm{Cdx} 2+/$ - mice develop an interesting kind of colonic lesion that does exhibit epithelial boundaries (Beck et al., 1999). The center of this lesion is characterized by stratified squamous epithelium similar to that of the esophagus and forestomach, and cells in this region are negative for $\mathrm{Cdx} 2$, as are the normal stomach and esophagus. Surrounding these Cdx2-negative cells are regions of heterotopic small intestinal mucosa (composed of Cdx2-positive cells), which separate the central lesions from the surrounding colon. This "intercalary" tissue is characterized by a sharp (one cell thick) border of $\mathrm{Cdx} 2$ gene expression at the "gastric-intestinal" boundary, similar to the border of villin/ $\beta$-galactosidase expression seen here at the pyloric border. It would be of interest to determine whether a "one-cell-thick" boundary of villin expression is also seen at these intercalary borders. If so, the time course of its formation, as determined by interbreeding this villin/ $\beta$-galactosidase allele onto the $\mathrm{Cdx} 2+/$ background, could reveal further aspects of this process of boundary formation.

The early villin/ $\beta$-galactosidase expression in the distal stomach cannot be accounted for by Cdx 2 , because this protein is not expressed in the stomach (James et al., 1994; Beck et al., 1995). However, the expression domain of $\mathrm{Pdx} 1$, another homeodomain protein, does extend into the distal stomach (Offield et al., 1996). Pdx1-deficient mice show defects in both duodenal and pancreatic morphogenesis and the pyloric region is morphologically altered (Offield et al., 1996). In efforts to dissect cis elements necessary for villin expression, we have recently detected particular cis elements that are specifically responsible for villin expression in the duodenum; deletion of these elements reduces transgene expression in the duodenum, but not the distal small intestine and colon (Madison et al., in preparation). These deleted regions also contain potential binding sites for $\mathrm{Pdx} 1$. Thus it is possible that early villin expression is largely under the control of $\mathrm{Pdx} 1$ in the duodenum and distal stomach.

These studies show that, in the adult, a remarkably sharp boundary of villin/ $\beta$-galactosidase expression between the stomach and the duodenum corresponds with an equally sharp morphologic border. The dramatic nature of this border (staining in one cell, with little or no staining in the adjacent cell) suggests that an important molecular change occurs in this region at this time and that this change may define two specific compartments. Indeed, boundaries between compartments are straight (reviewed in Dahmann and Basler, 1999 ), and the pyloric border, as visualized by $\beta$-galactosidase staining, is also straight. If this is a true compartment boundary, then its formation may involve a segregation mechanism. Differential strength of cell-cell adhesion has been proposed as one mecha- nism that might serve to sort cells at compartment boundaries (Dahmann and Basler, 1999). Recent studies by Smith and Tabin (2000) have demonstrated that cells in the developing pyloric mesoderm respect apparent compartment boundaries during development of stomach and intestine in the chick. Although this finding was not tested in the endoderm, it is possible that cells within this tissue also respect compartment boundaries. In Drosophila embryos, mitotic domain boundaries can define cell fate boundaries (Cambridge et al., 1997). Because in the gut, the proliferating stem cell compartment is not anchored in the crypts until after birth, it is possible that final epithelial pyloric border formation requires establishment of the differential domains of mitotic activity (very rapid in the intestine and slower in gastric tissue). The data presented in this report indicate that whatever the mechanism of border formation, villin represents a responding gene. Thus the further dissection of the villin regulatory program may also reveal the molecules responsible for the formation of this epithelial pyloric border.

An important aspect of epithelial pyloric boundary formation is its obvious relationship to tissue-specific identity. The pyloric boundary provides a sharp dividing line between stomach cells and intestinal cells. In some pathologic states, however, this boundary is not respected, and epithelial cells with intestine-like features can be found within the stomach or esophagus. These lesions, called intestinal metaplasias, are known precursors to cancer (Stemmermann, 1994). It is noteworthy that villin expression is detected in nearly $100 \%$ of intestinal metaplasias that develop in gastric and esophageal sites (Osborn et al., 1988; Regalado et al., 1998), although it is not seen in these sites normally (except for a very low basal expression level in the distal stomach). The consistency with which villin is expressed in intestinal metaplasias indicates that induction of villin in these lesions might be a part of the altered genetic program that gives rise to such lesions. Because intestinal metaplasias represent altered tissue identity, it is possible that the molecular mechanisms underlying their development is related to the epithelial identity decisions made at the pyloric border. We are currently using this villin/ $\beta$-galactosidase mouse model in conjunction with experimentally induced models of intestinal metaplasia in gastric tissue to explore this possibility.

Interestingly, we note that villin/ $\beta$-galactosidase expression respects epithelial borders in several tissues in addition to the pyloric epithelium. In the developing extraembryonic tissues, there is a sharp demarcation between the extraembryonic visceral endoderm, which shows continuous staining in columnar cells, and the embryonic visceral endoderm, which demonstrates discontinuous staining in squamous cells (Fig. 1). In the kidney, staining is seen in cells of the proximal tubules, but not distal tubules or collecting ducts (Fig. 4E). Finally, in the auditory system, only the anterior por- 
tion of the developing neuroepithelium is positive for $\beta$-galactosidase activity (Fig. $4 \mathrm{H}$ ). Identification of the villin regulatory elements that control expression at these borders will reveal whether the same or different sets of factors regulate each of these border decisions.

\section{EXPERIMENTAL PROCEDURES}

\section{Establishment of the Model and Collection of Embryos}

By using homologous recombination in mouse embryonic stem cells, the cDNA for $\beta$-galactosidase was inserted into the villin locus (Pinson et al., 1998). The insertion simultaneously removed a $4-\mathrm{kb}$ portion of the villin genomic sequences, beginning in exon 1 (the first translated exon), and extending to exon 4. This alteration disrupted villin transcript expression and resulted instead in the elaboration of a villin/ $\beta$-galactosidase fusion transcript encoding a protein containing the $18 \mathrm{~N}$-terminal amino acids of villin fused in frame to the $\beta$-galactosidase cDNA.

Pregnant females from matings between mice heterozygous for the insertion were killed by cervical dislocation. Embryos were staged by standard criteria (Downs and Davies, 1993; Kaufman, 1994), and a small piece of tissue (head or yolk sac) was removed for genotyping by polymerase chain reaction, by using primers that can detect wild-type, heterozygous, and homozygous states, as described in Pinson et al. (1998). Unless otherwise specified in the text, only embryos homozygous for the $\beta$-gal insertion were used in the analysis. Wild-type tissues from the same litter were processed in parallel to allow discrimination of background staining in some tissues (most prominent in adult kidney, stomach, and testes).

\section{Tissue Preparation for $\beta$-Galactosidase Staining in Whole-Mount and Paraffin-Embedded Sections}

Dissected embryos or tissues were placed on ice in $4 \%$ paraformaldehyde fixative (1.25 mM EGTA, $2 \mathrm{mM}$ $\mathrm{MgCl}_{2}$ in PBS) for $10 \mathrm{~min}$, then washed twice in PBS and placed in X-gal (5-bromo-4-chloro-3-indolyl- $\beta$-Dgalactoside) staining solution (1 $\mathrm{mg} / \mathrm{ml} \mathrm{X}$-gal in $\mathrm{N}, \mathrm{N}$-dimethylformamide, $5 \mathrm{mM} \mathrm{K} \mathrm{K}_{3} \mathrm{Fe}(\mathrm{CN})_{6}, 5 \mathrm{mM}$ $\mathrm{K}_{4} \mathrm{Fe}(\mathrm{CN})_{6^{-}}{ }^{3} \mathrm{H}_{2} \mathrm{O}, 2 \mathrm{mM} \mathrm{MgCl} \mathrm{Mg}_{2}, 0.02 \% \mathrm{NP}-40$ in $0.1 \mathrm{M}$ phosphate buffer, $\mathrm{pH} 8.0$ ) for $2-10 \mathrm{hr}$ at $37^{\circ} \mathrm{C}$, depending on embryo size and age. Careful monitoring of $\mathrm{pH}$ was important for the suppression of background staining. Wild-type tissues were processed simultaneously with tissues containing the villin/ $\beta$-galactosidase allele; staining was monitored and was stopped when $\beta$-gal containing tissues were clearly stained, and before significant background staining was visible in the controls. Stained tissues were washed twice in PBS, post-fixed for $10 \mathrm{~min}$ at room temperature with $0.2 \%$ glutaraldehyde (1.25 mM EGTA, $2 \mathrm{mM} \mathrm{MgCl}_{2}$ in PBS), washed again in $\mathrm{PBS}$, and further fixed in $4 \%$ paraformaldehyde for $6 \mathrm{hr}$ at $4^{\circ} \mathrm{C}$. Tissues were stored in $70 \%$ ethanol after partial dehydration in a graded ethanol series (30\%, 50\%, and 70\%, 10 min each). Whole-mount photographs were taken at this point.

For embedding, tissues were dehydrated in increasing ethanol concentrations of $85 \%, 95 \%$, and $100 \%$, and then cleared in Hemo De solvent. Paraffin infiltration was performed under vacuum three times for $20 \mathrm{~min}$, and the tissue was embedded in fresh wax. Sections (7-10 $\mu \mathrm{m}$ ) were generated, rehydrated, and counterstained in $0.25 \%$ eosin or $0.8 \%$ neutral red.

\section{Processing and $\beta$-Galactosidase Staining of Cryostat Sections}

$\beta$-Galactosidase expression was also examined after cryostat sectioning and staining. This process was particularly important in late embryos and postnatal samples as embryo growth impeded even stain penetration of whole tissues, producing artifactual staining patterns. Dissected tissues were fixed on ice in $4 \%$ paraformaldehyde for $10 \mathrm{~min}$, washed with ice cold PBS twice, and placed in O.C.T Compound (Tissue-Tek, Sakura Finetek USA, Torrance, CA) in Peel-Away Molds (Polysciences, Inc., Warrington, PA). Samples were snap frozen in liquid nitrogen and stored at $-80^{\circ} \mathrm{C}$ before sectioning.

Tissue sections, $8 \mu \mathrm{m}$ thick, were obtained by using a cryostat (MICROM HM500M, Germany) and collected onto poly-L-lysine coated slides. Frozen tissue sections were allowed to reach room temperature, washed twice in PBS, and incubated with X-gal staining solution, prepared as above. Incubation was performed in a moist chamber at $37^{\circ} \mathrm{C}$ for $\leq 16 \mathrm{hr}$. Stained sections were washed twice with ice cold PBS, dehydrated in $70 \%$ ethanol, followed by $83 \%$ EtOH, and counterstained with eosin for 15 to 30 sec. Sections were then further dehydrated with graded ethanol washes, cleared in Hemo De (Fisher Scientific, NJ), and coverslips were applied by using Permount (Fisher Scientific).

\section{Immunohistochemical Staining for Villin Protein}

Tissues were removed from C57BL6 mouse (Charles River Laboratories, Wilmington, MA) embryos (8.5, $9.5,10.5$, and $13.5 \mathrm{dpc}$ ), fixed in $4 \%$ paraformaldehyde for 4 to $6 \mathrm{hr}$ at $4^{\circ} \mathrm{C}$, dehydrated, and embedded in paraffin. A goat immunoglobulin $\mathrm{G}$ (IgG) polyclonal antibody to villin (C-19, Santa Cruz Biotechnology, CA) was used to detect villin expression in paraffin sections.

Tissue sections $(4 \mu \mathrm{m})$ on poly-L-lysine-coated slides were dried, deparaffinized in xylene, rehydrated in graded ethanols, and transferred to PBS. The tissue sections were soaked in Antigen Unmasking Solution (Vector Laboratories, CA), heated in a microwave at $89-93^{\circ} \mathrm{C}$ for $10 \mathrm{~min}$, and then allowed to cool at room temperature for $20 \mathrm{~min}$. After two consecutive washes in PBS, endogenous peroxidase activity was blocked by 
treatment with $30 \%$ hydrogen peroxidase in $100 \%$ methanol for $20 \mathrm{~min}$. Slides were rinsed with water and equilibrated with PBS containing $0.01 \%$ Triton X-100 (PBS/Triton). Rabbit serum (20\%) was used as a blocking agent for $20 \mathrm{~min}$, after which slides were incubated in a 1:50 dilution of anti-villin antibody for $1 \mathrm{hr}$ at room temperature. After brief washing, biotinylated-rabbit anti-goat IgG (1:200, Vector Laboratories) was applied for $30 \mathrm{~min}$. Color development was achieved by incubation in $\mathrm{ABC}$ working solution (Vector Laboratories) for 30 min followed by diaminobenzidine working solution with nickel solution (Vector Laboratories) for 5 min. Slides were not counterstained, as staining of early embryos was faint and easily obscured by the counterstain. Sections were then dehydrated and cover-slipped with Permount. Known positive (13.5 dpc fetal midgut) and negative (stomach) control specimens were stained within each run. This staining protocol results in the development of a grey-black color in villin-expressing tissues.

\section{ACKNOWLEDGMENTS}

We thank Ms. Christine Babcock for help with animal breeding and phenotyping. Technical and core support was obtained from the following Centers at The University of Michigan: the Center for Organogenesis, the Comprehensive Cancer Center and the Gastrointestinal Peptide Center. K.P. was supported by a Dean's Fellowship from the University of Michigan Center for Organogenesis; B.M. is supported by NIH "Training Program in Organogenesis"; and D.L.G. is the recipient of a Roger DeMeritt Research Fund Award from the University of Michigan Comprehensive Cancer Center.

\section{REFERENCES}

Beck F, Erler T, Russell A, James R. 1995. Expression of Cdx-2 in the mouse embryo and placenta: possible role in patterning of the extra-embryonic membranes. Dev Dyn 204:219-227.

Beck F, Chawengsaksophak K, Waring P, Playford RJ, Furness JB. 1999. Reprogramming of intestinal differentiation and intercalary regeneration in cdx2 mutant mice. Proc Natl Acad Sci U S A 96:7318-7323.

Boller K, Arpin M, Pringault E, Mangeat P, Reggio H. 1988. Differential distribution of villin and villin mRNA in mouse intestinal epithelial cells. Differentiation 39:51-57.

Catala M, Teillet M-A, Le Dourain NM. 1995. Organization and development of the tail bud analyzed with the quail-chick chimera system. Mech Dev 51:51-65.

Cambridge SB, Davis RL, Mindon JS. 1997. Drosophila mitotic domain boundaries as cell fate boundaries. Science 277:825-828.

Dahmann C, Basler K. 1999 Compartment Boundaries at the edge of development. Trends Genet 15:320-325.

Downs KM, Davies T. 1993. Staging of gastrulating mouse embryos by morphological landmarks in the dissecting microscope. Development 118:1255-1266.

Ezzell RM, Chafel MM, Matsudaira PT. 1989. Differential localization of villin and fimbrin during development of the mouse visceral endoderm and intestinal epithelium. Development 106: 407-419.

Gajovic S, Knezevic K, Svajger A. 1993. Morphological evidence for secondary formation of the tail gut in the rat embryo. Anat Embryol (Berl) 187:291-297.
Giordano TJ, Shedden KA, Schwartz DR, Kuick R, Taylor JM, Lee N, Misek DE, Greenson JK, Kardia SL, Beer DG, Rennert G, Cho KR, Gruber SB, Fearon ER, Hanash S. 2001. Organ-specific molecular classification of primary lung, colon, and ovarian adenocarcinomas using gene expression profiles. Am J Pathol 159: $1231-1238$.

Griffith CM, Wiley MJ Sanders EJ. 1992. The vertebrate tail bud: three germ layers from one tissue. Anat Embryol (Berl) 185:101113.

Huang HP, Tsai MJ. 2000. Transcription factors involved in pancreatic islet development. J Biomed Sci 7:27-34.

James R, Erler T, Kazenwadel J. 1994. Structure of the murine homeobox gene $c d x-2$. Expression in embryonic and adult intestinal epithelium. J Biol Chem 269:15229-15237.

Kaufman MH. 1994. The atlas of mouse development. London: Academia Press.

Kedinger M, Duluc I, Fritsch C, Lorenz O, Plateroti M, Freund JN. 1998. Intestinal epithelial-mesenchymal cell interactions. Ann N Y Acad Sci 859:1-17.

Keller RE. 1976. Vital dye mapping of the gastrula and neurula of Xenopus laevis. II. Prospective areas and morphogenetic movements of the deep layer. Dev Biol. 51:118-137.

Lammert E, Cleaver O, Melton D. 2001. Induction of pancreatic differentiation by signals from blood vessels. Science 294:564567.

Landry C, Huet C, Mangeat P, Sahuquet A, Louvard D, Crine P. 1994. Comparative analysis of neutral endopeptidase (NEP) and villin gene expression during mouse embryogenesis and enterocyte maturation. Differentiation 56:55-65.

Lawson KA, Pedersen RA. 1987. Cell fate, morphogenetic movement and population kinetics of embryonic endoderm at the time of germ layer formation in the mouse. Development 101:627-652.

Lim DJ, Anniko M. 1985. Developmental morphology of the mouse inner ear. A scanning electron microscopic observation. Acta Otolaryngol 422:1-69.

Maatman R, Zachgo J, Gossler A. 1997. The Danforth's short tail mutation acts cell autonomously in notochord cells and ventral hindgut endoderm. Development 124:4019-4028.

Matsumoto K, Yoshitomi H, Rossant J, Zaret KS. 2001. Liver organogenesis promoted by endothelial cells prior to vascular function. Science 294:559-563.

Maunoury R, Robine S, Pringault E, Huet C, Guenet JL, Gaillard JA, Louvard D. 1988. Villin expression in the visceral endoderm and in the gut anlage during early mouse embryogenesis. EMBO J 7:33213329 .

Maunoury R, Robine S, Pringault E, Leonard N, Gaillard JA, Louvard D. 1992. Developmental regulation of villin gene expression in the epithelial cell lineages of mouse digestive and urogenital tracts. Development 115:717-728.

Offield MF, Jetton TL, Labosky PA, Ray M, Stein RW, Magnuson MA, Hogan BL, Wright CV. 1996. PDX-1 is required for pancreatic outgrowth and differentiation of the rostral duodenum. Development 122:983-995.

Osborn M, Mazzoleni G, Santini D, Marrano D, Martinelli G, Weber K. 1988. Villin, intestinal brush border hydrolases and keratin polypeptides in intestinal metaplasia and gastric cancer; an immunohistologic study emphasizing the different degrees of intestinal and gastric differentiation in signet ring cell carcinomas. Virchows Arch Pathol Anat Histopathol 413:303-312.

Pinson K, Dunbar L, Samuelson L, Gumucio D. 1998. Targeted disruption of the mouse villin gene does not impair the morphogenesis of microvilli. Dev Dyn 211:109-121.

Regalado SP, Nambu Y, Iannettoni MD, Orringer MB, Beer DG. 1998. Abundant expression of the intestinal protein villin in Barrett's metaplasia and esophageal adenocarcinomas. Mol Carcinog 22:182-189.

Rosenquist GC. 1971. The location of the pregut endoderm in the chick embryo at the primitive streak stage as determined by radioautographic mapping. Dev Biol 26:323-335. 
Silberg DG, Furth EE, Taylor JK, Schuck T, Chiou T, Traber PG. 1997. CDX1 protein expression in normal, metaplastic and neoplastic human alimentary tract epithelium. Gastroenterology 113:478486.

Silberg DG, Swain GP, Suh ER, Traber PG. 2000. Cdx1 and Cdx2 expression during intestinal development. Gastroenterology 119: 961-971.

Smith DM, Tabin CJ. 2000. Clonally related cells are restricted to organ boundaries early in the development of the chicken gut to form compartment boundaries. Dev Biol 227:422431.
Smith DM, Grasty RC, Theodosiou NA, Tabin CJ, Nascone-Yoder NM. 2000. Evolutionary relationships between the amphibian, avian and mammalian stomachs. Evol Dev 2:348-359.

Stemmermann GN. 1994. Intestinal metaplasia of the stomach. A status report. Cancer 74:556-564.

Wells JM, Melton DA. 1999. Vertebrate endoderm development. Annu Rev Cell Dev Biol 15:393-410.

Wilson V, Beddington RSP. 1996. Cell fate and morphogenic movement in the late mouse primitive streak. Mech Dev 55:70-89.

Zaret KS. 2000. Liver specification and early morphogenesis. Mech Dev 92:83-88. 